\title{
Effect of an Inhibitor of Glucosylceramide Synthesis on Cultured Human Keratinocytes
}

\author{
Yoshihiro Takami ${ }^{1.3}$, Akira Abe'2, Takayoshi Matsuda ${ }^{3}$, James A. Shayman², \\ Norman S. Radin ${ }^{2}$ and Robert J. Walter ${ }^{3}$
}

\begin{abstract}
Glucosylceramide (GlcCer) is a major glycosphingolipid component of epidermis, which is thought to be related to the barrier function of skin permeability. However, the role of glycosphingolipids in keratinocyte growth and differentiation has not been fully clarified. It has been reported that D-threo-1-phenyl-2-decanoylamino-3-morpholino-1propanol (PDMP), an inhibitor of GlcCer synthase (EC 2.4.1.80), depletes cells of glycosphingolipids. This inhibitor has been used as a tool for elucidating their functions. In the present study, the effect of PDMP on cultured normal human keratinocytes was investigated. The cells were treated with various concentrations of PDMP. Forty-eight hours later cell growth, thymidine incorporation, and lipid content were studied. The cell growth and the incorporation of thymidine into cells were inhibited by PDMP in a dose dependent manner. The synthesis of GlcCer was strongly inhibited by PDMP treatment, whereas no significant changes in ceramide level were observed. We concluded that GlcCer in epidermis may play an important role in regulating epidermal growth and suggested that PDMP may be beneficial for treating proliferative skin disorders in the future.
\end{abstract}

Key words: keratinocytes; glucosylceramide; cell growth

\section{Introduction}

Recently, many studies using normal and transformed cells have shown that glycosphingolipids derived from GlcCer are involved in a range of physiological activities including cell proliferation, cell diferentiation, and apoptosis (1-5). These lipids have been proposed to act through regulation of cell kinases, phosphatases, and gene transcription $(4,5)$. On the basis of these studies, it is suggested that glycosphingolipids in the epi-

Received July 31, 1997; accepted for publication November 12, 1997.

"Department of Plastic Surgery, Kyorin University, Tokyo, Japan.

${ }^{2}$ Department of Internal Medicine, University of Michigan Medical Center, Ann Arbor, MI, USA.

${ }^{4}$ Burn Unit and Department of Surgery, Hektoen Institute, Cook County Hospital, Chicago, IL, USA.

Reprint requests to: Yoshihiro Takami, M.D., Department of Plastic Surgery, Kyorin University, School of Medicine, 6-20-2, Shinkawa, Mitaka, Tokyo 181 , Japan. dermis might also play an important role in regulating these cellular events.

It has been reported that D-threo-1phenyl-2-decanoylamino-3-morpholino-1propanol (PDMP), an inhibitor of GlcCer synthase (EC 2.4.1.80), depletes cells of glycosphingolipids (6-8). Therefore, this inhibitor has been used as a tool for elucidating their functions. It has inhibited proliferation of cultured normal cells (9), has shown chemotherapeutic action in cancer $(10,11)$, and has reduced the ability of cancer cells to metastasize $(12,13)$. However, the studies of the effects of this GlcCer synthase inhibitor on keratinocytes have been limited (14). In the present study, we investigated the effect of PDMP on the proliferation and lipid contents of cultured human keratinocytes.

\section{Materials and Methods}

Cell Culture

Normal human keratinocytes from healthy 


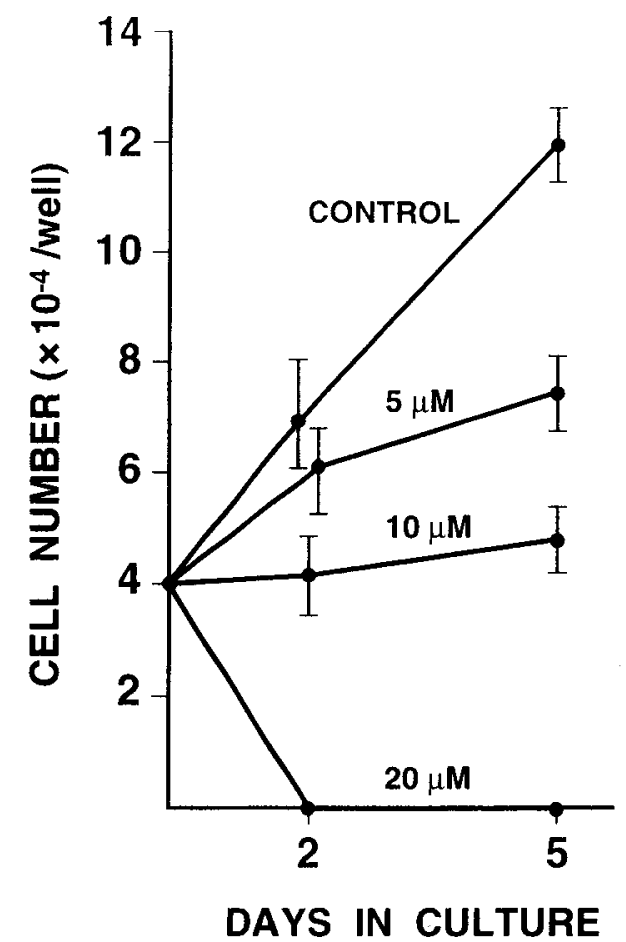

Fig. 1. Effect of PDMP on Keratinocyte Growth. The concentrations of PDMP in $\mu \mathrm{M}$ added to the culture medium are indicated in the figure. Each value indicate the mean $\pm S D$ in triplicate wells.

adult skin were cultured using a modification of a previously described method (15). The cells were grown in keratinocyte growth medium, KGM (Keratinocyte SFM, Gibco, BRL, Grand Island, NY, USA) at $37^{\circ} \mathrm{C}$ in $5 \% \mathrm{CO}_{2} / 95 \%$ air. $\mathrm{KGM}$ contained $2.5 \mathrm{ng} / \mathrm{ml}$ epidermal growth factor, $35 \mu \mathrm{g} / \mathrm{ml}$ bovine pituitary extract, and $0.09 \mathrm{mM} \mathrm{CaCl}{ }_{2}$. All experiments were carried out using third or fourth passage keratinocytes grown in KGM as described previously (16).

\section{Effects of PDMP on cell proliferation}

The stock solution of $1.92 \mathrm{mM}$ PDMP (Biomol Research Laboratories, Inc. PA, USA)-140 $\mathrm{mM}$ fatty acid-free bovine serum albumin (Sigma, St. Louis. Mo., USA) complex was prepared as described elsewhere ( 7$)$. Cells $(4 \times$ $10^{4} /$ well) were seeded into 24-well culture plates (Corning Glass Works, NY, USA) coated with 25 $\mu \mathrm{g} / \mathrm{ml}$ type IV collagen (Gibco BRL, USA) and incubated at $37^{\circ} \mathrm{C}$ in $5 \% \mathrm{CO}_{2} / 95 \%$ air. Eight hours after seeding, by which time most of the cells had attached to the floor of the well, PDMP ( 0 to $40 \mu \mathrm{M}$ in $\mathrm{KGM}$ ) was added to the wells. Two days and five days later, the wells were washed with PBS, and the cells were dissociated with $0.25 \%$ trypsin. Following testing with trypan blue, the number of viable cells was measured using a hemocytemeter.

Effect of PDMP on DNA synthesis

Cells $\left(1 \times 10^{5} /\right.$ well $)$ were seeded into 24 -well culture plates coated with type IV collagen and incubated for $24 \mathrm{~h}$ at $37^{\circ} \mathrm{C}$ in $5 \% \mathrm{CO}_{2} / 95 \%$ air. After this incubation, cells were exposed for $48 \mathrm{~h}$ to various concentrations of PDMP dissolved in KGM. The cells were incubated with 4 $\mu \mathrm{Ci} / \mathrm{ml}\left[{ }^{3} \mathrm{H}\right]$ thymidine (Amersham, Arlington, Ill. USA) for the last $8 \mathrm{~h}$ of the PDMP treatment. They were then washed 3 times with PBS. Then $0.5 \mathrm{ml}$ of $1 \mathrm{~N} \mathrm{NaOH}$ was added to each well, and the sample was counted using a scintilation counter (Beckman, USA).

Reversibility of the PDMP effect on ['H] thymidine incorporation

In order to determine the toxicity of lower concentrations of PDMP, the following study was carried out. Cells were cultivated in a $75 \mathrm{~mm}^{2}$ culture dish (Corning Glass Works, NY, USA) coated with type IV collagen as described above and treated with or without $10 \mu \mathrm{M}$ PDMP in $\mathrm{KGM}$ for $48 \mathrm{~h}$. The cells were then washed with PBS 3 times and dissociated with $0.25 \%$ trypsin. After centrifugation ( $500 \mathrm{rpm} \times 10 \mathrm{~min})$, the cells $\left(1 \times 10^{5} /\right.$ well $)$ were placed in 24-well culture plates coated with type IV collagen and cultured with KGM for another $48 \mathrm{~h}$. For the final 8 hours of the culture, cells were labeled with $\left[{ }^{3} \mathrm{H}\right]$ thymidine and counted as described above.

Lipid analysis

Cells grown in 6-well culture plates (Corning Glass Works, NY, USA) coated with type IV collagen were incubated for 48 hours with or without PDMP. The cells then were washed 3 times with cold PBS and trypsinized. The resultant cell suspension was then centrifuged, and the pellet was fixed with methanol (M). To extract lipids, an equal volume of chloroform (C) was added to each tube, and the tube was sonicated for 15 min in an ultrasonic bath. After centrifuging for $20 \mathrm{~min}$ at $2000 \times \mathrm{g}$, the pellet was again extracted with a mixture of $\mathrm{C}: \mathrm{M}=1: 1$ and centrifuged as 


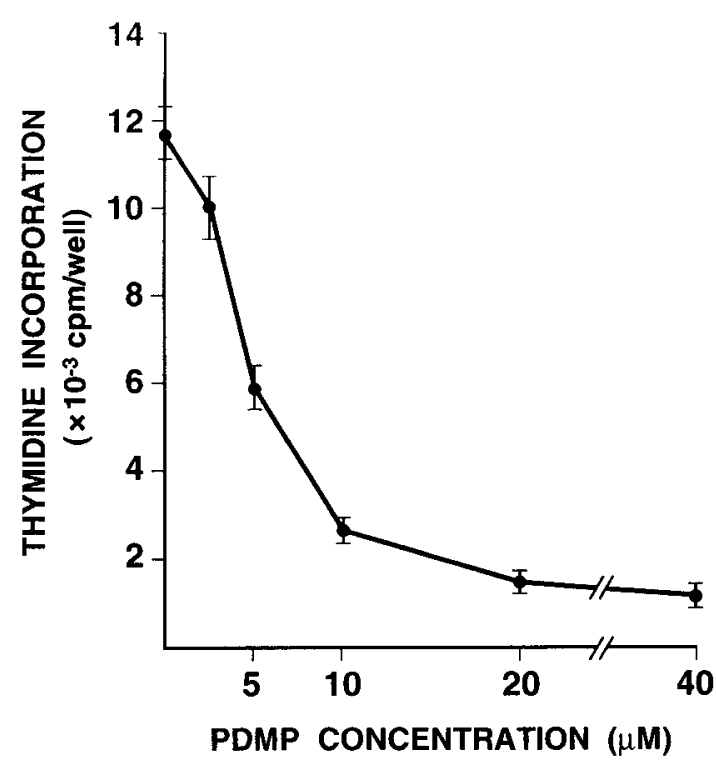

Fig. 2. Effect of PDMP on $\left[{ }^{3} \mathrm{H}\right]$ thymidine incorporation into DNA of keratinocytes. Each value indicates the mean $\pm \mathrm{SD}$ in triplicate wells.

described above. The resulting supernatants were combined, and $0.9 \% \mathrm{NaCl}$ was added until the ratio of $\mathrm{C}: \mathrm{M}: \mathrm{NaCl}=2: 1: 0.8$ to obtain phase separation. This mixture was vortexed and then centrifuged for $5 \mathrm{~min}$ at $800 \times \mathrm{g}$. The upper phase was discarded, and lower phase was again mixed with methanol and $0.9 \% \mathrm{NaCl}$; the ratio of C:M:aqueous was 2:1:0.8. After centrifugation, the lower phase was transferred to another tube and dried under a stream of nitrogen gas. A part of the dried lipids dissolved in C:M (2:1) was applied to an HPTLC plate (E. Merck silica gel 60). Solvent systems consisting of C:M:W (24:7:1) and C:acetic acid (9:1) were used for GlcCer and Cer analysis, respectively.

Statistical analysis

Each study was triplicated. Non-paired t-analysis was used for the statistical analysis.

\section{Results}

\section{Effect of PDMP on cell proliferation}

Cell proliferation was inhibited by PDMP in a dose-dependent manner. Below the concentration of $20 \mu \mathrm{M}$, the effect of PDMP was not cytotoxic, and the cell viability was assured by the trypan blue dye exclusion
Table 1. Recovery of $\left[{ }^{3} \mathrm{H}\right]$ thymidine incorporation of keratinocytes after PDMP treatment

\begin{tabular}{lc}
\hline \hline & CPM \\
\hline Control & $11345 \pm 719$ \\
PDMP $(10 \mu \mathrm{M})$ & $10965 \pm 191$ \\
\hline
\end{tabular}

Each value indicates mean $\pm \mathrm{SD}$ in triplicate wells. There were no significant differences between the two groups.

Table 2. Effect of PDMP on glycosphingolipids synthesis

\begin{tabular}{lll}
\hline \hline & \multicolumn{1}{c}{ GlcCer } & Cer \\
\hline Control & $1.06 \pm 0.02$ & $1.22 \pm 0.08$ \\
PDMP $(5 \mu \mathrm{M})$ & $0.08 \pm 0.01^{*}$ & $1.30 \pm 0.03$ \\
\hline
\end{tabular}

The cells were incubated for $48 \mathrm{hr}$ in culture medium with or without $5 \mu \mathrm{M}$ PDMP. Each value indicates the mean \pm SD of glucosylceramide (GlcCer) or ceramide (Cer) content $(\mu \mathrm{g} / \mathrm{mg}$ protein) in triplicated determinations. ${ }^{*} \mathrm{p}<0.05$ in comparison with control.

test. However, at concentrations of more than $20 \mu \mathrm{M}$, cell death was observed in most of the keratinocytes (Fig. 1).

Effect of PDMP on $\left[^{3} \mathrm{H}\right]$ thymidine incorporation

$\left[{ }^{3} \mathrm{H}\right]$ thymidine incorporation into cells was inhibited by 48 hours of treatment with PDMP in a dose-dependent manner. At the concentration of $5 \mu \mathrm{M},\left[{ }^{3} \mathrm{H}\right]$ thymidine incorporation was reduced to about $50 \%$ of the control level (Fig. 2).

Reversibility of the PDMP effect on $\left[{ }^{3} \mathrm{H}\right]$ thymidine incorporation

Cells that were incubated for $48 \mathrm{~h}$ in PDMP-free medium after pretreatment with $10 \mu \mathrm{M}$ of PDMP showed complete recovery (98\% of controls) of the ability to incorporate thymidine into cells (Table 1 ).

Lipid analysis

GlcCer synthesis was strongly inhibited by $5 \mu \mathrm{M}$ PDMP (Table 2). The concentration of GlcCer ( $\mu \mathrm{g} / \mathrm{mg}$ protein) was reduced to 
7 or $8 \%$ of the control value. The change in Cer level was not significant after $48 \mathrm{~h}$ of treatment with $5 \mu \mathrm{M}$ of PDMP.

\section{Discussion}

Glycosphingolipids, especially acylGlcCer, have been shown to be major forms of GlcCer in the basal and prickle layers of epidermis and to hydrolyze to ceramide as the cells become horny (17-20). The physiological function of GlcCer in basal cells has been unclear; however, recently Holleran et al. indicated that GlcCer serves to stimulate cell proliferation and that its conversion to ceramide as the cells rise toward the skin surface results in differentiation and loss of proliferation $(21,22)$. Our results demonstrated that PDMP significantly depleted the GlcCer of cultured human keratinocytes, which are thought to reflect the characteristics of the basal keratinocytes, and inhibited both their growth and $\left[{ }^{3} \mathrm{H}\right]$ thymidine incorporation. These findings are consistent with the results of previous reports using other cell lines and tissues. However, the mechanism of the effect of PDMP and the relationship between GlcCer depletion and growth inhibition are not fully understood. Recently, it has been reported that sphingomyelin breakdown products regulate cell growth, differentiation, and apoptosis (1-5). In this metabolic turnover of sphingomyelin, sphingosine and ceramide are thought to have major functional roles. From this point of view, it may be an important question whether GlcCer is the major candidate for the inhibition of cellular growth by PDMP treatment. Using a transformed human keratinocyte cell line, Wakita et al. reported that cell-permeant ceramides inhibited cell growth and induced cell differentiation (3). In our study, by $48 \mathrm{~h}$ treatment with PDMP, at which time keratinocyte growth was strongly inhibited, only the GlcCer level was reduced; the change in Cer level was not significant. This result suggests that GlcCer regulates such cellular function by itself. However, it is also possible that changes in the ratio of GlcCer/Cer related to sphin- gomyelin metabolism may be a important signal for regulation of keratinocyte function. Further study of the changes in sphingolipid composition by PDMP treatment is needed to clarify the mechanism of PDMP effects. Moreover, it is also important to investigate whether keratinocyte differentiation and apoptosis are induced by PDMP treatment.

PDMP has been expected to be useful as a new drug in cancer chemotherapy $(10,11)$. However, it has not yet been used clinically because its pharmacological safety and toxicity have not been established. If PDMP was administered systemically, the depletion of the cellular GlcCer level must occur in many normal tissues and may result in damage to them (10). However, it is possible that such systemic side effects may be avoided or reduced if PDMP is applied topically. There are many kinds of neoplastic or non-neoplastic proliferative skin disorders. Psoriasis is the most common and benign of these; squamous cell carcinoma is the most common skin cancer. Since PDMP inhibited epidermal cell growth, this substance may have therapeutic value in treating such proliferating skin disorders when applied topically. Our result also suggests that the effect of PDMP is reversible and not toxic at its lower concentration. So it is possible that the toxicity to surrounding normal tissue by PDMP topical application may be less than that resulting from topical chemotherapy using other anti-proliferative ointments such as 5fluorouracil ointment. Further pharmacological studies are needed to confirm the benefit of PDMP for topical therapy of such skin diseases in the future.

\section{References}

1) Okazaki T, Bell RM, Hannun YA: Sphimgomyelin turnover induced by vitamin D3 in $\mathrm{HL}$ 60 cells. Role in cell differentiation, J Biol Chem, 264: 19076-19080, 1989.

2) Holleran WM: Lipid modulators of epidermal proliferation and differentiation, Adv Lipid Res, 24: 119-139, 1991.

3) Wakita H, Tokura Y, Yagi H, Nishimura K, Furukawa $\mathrm{F}$, Takigawa $\mathrm{M}$ : Keratinocyte differentia- 
tion is induced by cell-permeant ceramides and its proliferation is promoted by sphingosine, Arch Dermatol Res, 286: 350-354, 1994.

4) Hannun YA, Bell RM: Functions of sphingolipids and sphingolipid breakdown products in cellular regulation, Science, 243: 500-507, 1989.

5) Shayman JA: Sphingolipids: Their role in intracellular signaling and renal growth, $J A m$ Soc Nephrol, 7: 171-182, 1996.

6) Inokuchi J, Radin NS: Preparation of the active isomer of 1-phenyl-2-decanoylamino-3-morpholino-1-propanol, inhibitor of murine glucocerebroside synthase, $J$ Lipid Res, 28: 565-571, 1987.

7) Abe A, Inokuchi J, Jimbo $M$, et al: Improved inhibitors of glucosyl; ceramide synthase, $J$ Biochem, 111: 191-196, 1992.

8) Abe A, Radin NS, Shayman JA, et al: Structural and stereochemical studies of potent inhibitors of glucosyl ceramide synthase and tumor cell growth, J Lipid Res, 36: 611-621, 1995.

9) Uemura K, Sugiyama E, Tamai C, Hara A, Taketomi T, Radin NS: Effect of an inhibitor of glucosylceraminde synthesis on cultured rabbit skin fibroblasts, J Biochem, 108: 525-530, 1990.

10) Inokuchi J, Mason I, Radin NS: Antitumor activity via inhibition of glycosphingolipid biosynthesis, Cancer Lett, 38: 23-30, 1987.

11) Kyogashima $M$, Inoue $M$, Seto $A$, Inokuchi J: Glucosylceramide synthase inhibitor, D-threo-1phenyl-2-decanoylamino-3-morpholino-1propanol exhibits a novel decarnogenic activity against Shope carcinoma cells, Cancer Lett, 101: 25-30, 1996.

12) Inokuchi J, Momosaki $K$, Shimeno $H$, Nagamatsu A, Radin NS: Effects of D-threo-PDMP, an inhibitor of glucosylceramide synthase, on expression of cell surface glycolipid antigen and binding to adhesive proteins by B16 melanoma cells, J Cell Physiol, 141: 573-583, 1989.

13) Inokuchi J, Jimbo M, Momosaki K, Shimeno $H$,
Naganatsu $A$, Radin NS: Inhibition of experimental metastasis of murine Lewis lung carcinoma by an inhibitor of glucosylceramide synthase and its possible mechanism of action, Cancer Res, 50: 6731-6737, 1990.

14) Sando GN, Howard EJ, Madison KC: Induction of ceramide glucosyltransferase activity in culture human keratinocytes correlation with culture differentiation, $J$ Biol Chem, 271: 22044-22051, 1996.

15) Boyce ST, Ham RG: Calcium regulated differentiation of normal human epidermal keratinocytes in chemically defined clonal culture and serum free serial culture, J Invest Dermatol, 81: 33s-40s, 1983.

16) Bikle DD, Gee E, Pillai S: Regulation of keratinocyte growth, differentiation, and vitamin $\mathrm{D}$ metabolism by analog of 1,25-dehydroxyvitamin D, J Invest Dermatol, 101: 713-718, 1993.

17) Gray GM, Yardley HJ: Lipid compositions of cells isolated from pig, human, and rat epidermis, $J$ Lipid Res, 16: 434-440, 1975.

18) Lampe MA, Burlingame AL, Whitney J, et al: Human stratum corneum lipids: characterization and regional variations, $J$ Lipid Res, 24: 120-130, 1983.

19) Lampe MA, Williams ML, Elias PM: Human epidermal lipids: characterization and modulations during differentiation, J Lipid Res, 24: 131-140, 1983.

20) Hanaoka S, Takemoto $T$, Hamanaka $Y$, et al: Structure determination of glycosphingolipids of cultured human keratinocytes, Biochim Biophys Acta, 1167: 1-8, 1993.

21) Holleran WM, Feingold KR, Mao-Qiang M, Gao WN, Lee JM, Elias PM: Regulation of epidermal sphingolipid synthesis by permeability barrier function, J Lipid Res, 32: 1151-1158, 1991.

22) Marsh NL, Elias PM, Holleran WM: Glucosylceramides stimulate murine epidermal hyperproliferation, J Clinic Invest, 95: 2903-2909, 1995. 